American Journal of Infectious Diseases 5 (4): 294-300, 2009

ISSN 1553-6203

(C) 2009 Science Publications

\title{
Practical and Novel Sterilization Approach for the Pathogenic Staphylococcus aureus Bacteria
}

\author{
${ }^{1}$ Raftari Mohammad, ${ }^{2}$ Azizi Jalilian Farid, ${ }^{2}$ A.S. Abdulamir, ${ }^{1}$ Son Radu, \\ ${ }^{2}$ Sekawi Zamberi and ${ }^{1}$ Fatimah Abu Bakar \\ ${ }^{1}$ Faculty of Food Science and Technology, University Putra Malaysia, 43300, \\ Serdang, Selangor, Malaysia \\ ${ }^{2}$ Faculty of Medicine and Health Science, University Putra Malaysia, 43300, \\ Serdang, Selangor, Malaysia
}

\begin{abstract}
Problem statement: Decontaminating meat surfaces has been the big concern of meat industry. Thus, various intervention strategies have been studied to reduce the level of bacteria on animals' carcass surfaces. Approach: Mixture of different concentrations 1, 1.5 and 2\% of acetic, lactic, propionic and formic acids at 1:1 ratio were spray washed on inoculated meat to evaluate their efficacy in reducing numbers of Staphylococcus aureus on meat tissue at $4 \pm 1^{\circ} \mathrm{C}$. The beef pieces were decontaminated with hot water and then inoculated with $S$. aureus which then were spray washed with treatments for $15 \mathrm{sec}$ separately. Results: Spray wash combinations of acetic and formic, lactic and formic and propionic and formic acids reduced the number of $S$. aureus at a range of 1.18-1.43 $\log \mathrm{cfu} \mathrm{mL}^{-1} \mathrm{more}$ than combinations of acetic and lactic, acetic and propionic and lactic and propionic acids on meat tissue. Increasing the concentration of used acids increased the lethality of treatments as lethal effect of $2 \%$ concentration $>1.5 \%$ concentration $>1 \%$ concentration. Conclusion: Lactic and formic acids Combination showed the strongest lethal effect on $S$. aureus among other treatments. Moreover, this study showed that the combination of lactic and formic acids treatment is a feasible, safe, and economical decontamination method which is highly recommended for use rather than other combinations or single organic acids.
\end{abstract}

Key words: Beef, Staphylococcus aureus, acetic acid, lactic acid, propionic acid and formic acid

\section{INTRODUCTION}

Organic acids are weak acids that are commonly found in fruit juices and fermented foods ${ }^{[1]}$. Organic acids have a long history of being applied as food additives and preservatives for preventing food deterioration and extending the shelf-life of perishable food ingredients ${ }^{[2]}$. Organic acids are Generally Recognized As Safe (GRAS) antimicrobial agent and the dilute solutions of organic acids (1-3\%) are generally without effect on the desirable sensory properties of meat when used as a carcass decontaminant ${ }^{[3,4]}$.

Various researchers indicated the antibacterial effect of different types of organic acids ${ }^{[5-8]}$. Usage of organic acids could reduce the population of bacteria on meat surface, even though the reductions were statistically significant, but they did not yet found sufficient, therefore, researchers attempted to find the new treatments, which can increase the lethality effect of organic acids. To this end, organic acids were mixed with each other or with other antibacterial agents.

The effect of combination of organic acids with other antibacterial agents such as silver ions ${ }^{[9]} \operatorname{copper}^{[10]}$ and hydrogen peroxide ${ }^{[11]}$ has been studied. The results of these studies indicated stronger antibacterial effect compared with organic acids alone. However, these treatments might have undesirable effects caused by the residual trace of silver, copper and hydrogen peroxide on meat surface. Therefore, there is a grave need to test multiple combinations of different organic acids spray washed on inoculated meat.

To the best of our knowledge, there was no previous study investigated a large number of two organic acids combinations at different concentrations for controlling different bacteria on meat all at once. Previous studies focused on limited treatments for controlling bacteria in which results were inconsistent because of the extensive variations in conditions of experiments. Accordingly, this study compared the

Corresponding Author: Fatimah Abu Bakar, Faculty of Food Science and Technology, University Putra Malaysia, Serdang, 43400, Selangor, Malaysia 
antibacterial effect of different two acid combinations of acetic, lactic, propionic and formic acids at 1:1 ratio on inoculated $S$. aureus on meat. The objective of this study was to investigate, compare and adjust the antibacterial effect of the studied treatments on the inoculated $S$. aureus on meat at $4 \pm 1{ }^{\circ} \mathrm{C}$.

\section{MATERIALS AND METHODS}

Organic acids: Three concentrations, $1,1.5$ and $2 \%$, of organic acids that were used in combinations of two organic acids at 1:1 ratio were obtained by diluting glacial Acetic Acid (100\%), L-Lactic Acid (90\%), Propionic Acid (99\%) and Formic Acid (90\%) (Merck, Germany) in sterile Distilled Water (DW) as mentioned in Table 1.

Meat preparation: Fresh meat was obtained from a local butchery in Serdang, Selangor, Malaysia. Having been packed in sterile bags, the meat was transported to laboratory in a cool box. The samples were prepared immediately after transferring meat to the laboratory. Several 10-gram pieces of meats were procured from freshly slaughtered cow.

Bacterial strains: Staphylococcus aureus ATCC 29247 obtained from the American Type Culture Collection (ATCC).

Sample preparation: $S$. aureus was cultured on standard plate count agar (Merck, Germany) and was then incubated for $24 \mathrm{~h}$ at $37^{\circ} \mathrm{C}$. After $24 \mathrm{~h}$ of incubation, a number of colonies were inoculated in sterile DW and the cell concentration was adjusted to $10^{3}$ bacteria $\mathrm{mL}^{-1}$.

The prepared $10 \mathrm{~g}$ pieces of meat were decontaminated by washing with hot sterile $\mathrm{DW}\left(80^{\circ} \mathrm{C}\right)$ for $30 \mathrm{sec}^{[12]}$ then they were kept for few minutes to reach room temperature. At this stage, about $10^{3}$ bacteria $\mathrm{mL}^{-1[13]}$ of $S$. aureus was inoculated on decontaminated meat by pouring and swabbing over the meats surfaces ${ }^{[14]}$. Subsequently, the inoculated meats with selected bacterium were kept for 20 min to allow attachment and absorption of bacteria however, some of the inoculated meats were kept as an inoculation control $^{[6]}$.

After $20 \mathrm{~min}$, the inoculated meat was spray washed with organic acids for $15 \mathrm{sec}$ individually ${ }^{[11]}$. Once the inoculated meat was spray washed and drained, they were packed in sterile bags that were stored at $4 \pm 1^{\circ} \mathrm{C}$. Another set was also prepared at the same time as a replicate.
Table 1: The different two organic acids combinations for acetic, lactic, propionic and formic acids at $1,1.5$ and $2 \%$ concentrations

Acetic-lactic (AALA \%) $\quad$ (AALA 1) (AALA 1.5) $\quad$ (AALA 2)

Acetic-propionic (AAPA \%) (AAPA 1) (AAPA 1.5) (AAPA 2)

Acetic-formic (AAFA \%) (AAFA 1) (AAFA 1.5) $\quad$ (AAFA 2)

$\begin{array}{llll}\text { Lactic-propionic (LAPA \%) } & \text { (LAPA 1) (LAPA 1.5) } & \text { (LAPA 2) }\end{array}$

Lactic-formic (LAFA \%) (LAFA 1)

Propionic-formic (PAFA \%) $\quad$ (PAFA 1) $\quad$ (PAFA 1.5) $\quad$ (PAFA 2)

Microbiological analyses were carried out immediately after spray washing until the 12th day of refrigeration. The surface $\mathrm{pH}$ of samples was measured by using flat probe $\mathrm{pH}$ meter (Prescisa, Switzerland) on $0,2 \mathrm{nd}, 6$ th and 12th days of storage. At this step, each piece of meat $(10 \mathrm{~g})$ was aseptically blended with $90 \mathrm{~mL}$ of sterile peptone water (Merck, Germany) in a laboratory blender ${ }^{[15]}$. After that, $1 \mathrm{~mL}$ of the blended sample of each inoculated meat with $S$. aureus was transferred onto Petri dishes for pour plate culturing with standard plate count agar (Merck, Germany) individually. Again, another one $\mathrm{ml}$ of the same suspension was cultured as a duplicate. The Petri dishes were then incubated for $24 \mathrm{~h}$ at $37^{\circ} \mathrm{C}$. After $24 \mathrm{~h}$ of incubation, the number of colonies was enumerated in each Petri dish.

Statistical analysis: The bacterial population (CFU $\mathrm{mL}^{-1}$ ) was obtained from four replications performed on separate days and their means were converted to $\log _{10} \mathrm{CFU} \mathrm{mL}^{-1}$. Differences between $\log _{10} \mathrm{CFU} \mathrm{mL} \mathrm{m}^{-1}$ of untreated beef carcass tissue and $\log _{10} \mathrm{CFU} \mathrm{mL} \mathrm{mL}^{-1}$ of treated beef carcass tissue were calculated as $\log$ reduction $^{[16,11]}$. Log reductions of treatments were compared by Analysis Of Variance (ANOVA) test using the general linear models of SPSS 12.0 for windows, $\mathrm{P}$ value $<0.05$ was considered as significant.

\section{RESULTS}

The initial surface $\mathrm{pH}$ of meat decreased directly after spray washing with treatments. With progress of storage, it increased while the $\mathrm{pH}$ of untreated decreased. A significant $(\mathrm{p}<0.05)$ reductions were found in the population of $S$. aureus after being spray washed with all treatments.

The mean $\log$ reductions of $S$. aureus showed $1.60 \pm 0.5, \quad 1.79 \pm 0.5$ and $1.98 \pm 0.5 \quad \log _{10}$ cfu $\mathrm{mL}^{-1}$ reductions after being exposed to AALA at $1,1.5$ and $2 \%$ concentrations (Fig. 1a) and at $\mathrm{pH}$ range 4.37-5.56, 4.26-5.45 and 4.18-5.40 respectively. 1.42 \pm 0.5 , $1.55 \pm 0.5$ and $1.73 \pm 0.5 \log _{10} \mathrm{cfu} \mathrm{mL}^{-1}$ reductions after 
being exposed to AAPA at 1, 1.5 and $2 \%$ concentrations (Fig. 1b) and at $\mathrm{pH}$ range 4.63-5.78, 4.50-5.69 and $4.41-5.63$ respectively. 3.16 \pm 0.5 , $3.16 \pm 0.5$ and $3.16 \pm 0.5 \log _{10} \mathrm{cfu} \mathrm{mL}^{-1}$ reductions after spray washed with AAFA at $1,1.48 \pm 0.5,1.67 \pm 0.5$ and $1.88 \pm 0.5 \log _{10} \mathrm{cfu} \mathrm{mL}^{-1}$ reductions after being exposed to LAPA at $1,1.5$ and $2 \%$ concentrations (Fig. 1d) and at $\mathrm{pH}$ range 4.38-5.54, 4.27-5.48 and 4.15-5.37 respectively. As $3.16 \pm 0.5, \quad 3.16 \pm 0.5$ and

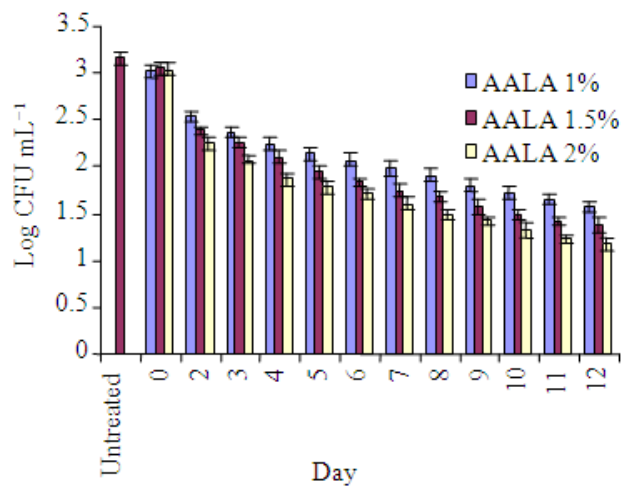

(a)

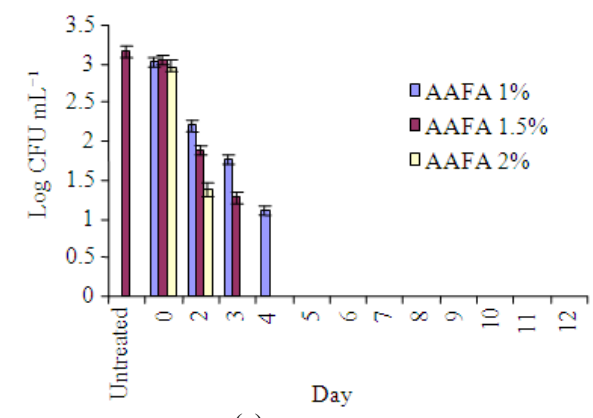

(c)

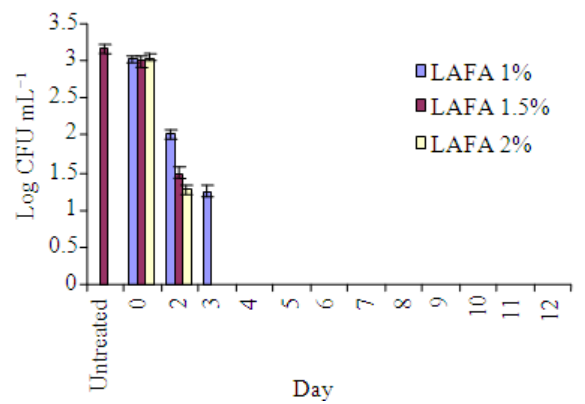

(e)
$3.16 \pm 0.5 \log _{10}$ cfu $\mathrm{mL}^{-1}$ reductions after being exposed to LAFA at 1, 1.5 and $2 \%$ concentrations (Fig. 1e) and at $\mathrm{pH}$ range 4.07-5.28, 3.93-5.19 and 3.82-4.08 respectively. As $3.16 \pm 0.5, \quad 3.16 \pm 0.5$ and $3.16 \pm 0.5 \log _{10}$ cfu $\mathrm{mL}^{-1}$ reductions after spray washed with PAFA at 1, 1.5 and 2\% concentrations (Fig. 1f) and at $\mathrm{pH}$ rang 4.18-5.40, 4.06-5.29 and 3.95-5.20 respectively. The untreated meat showed no significant changing in the population at $\mathrm{pH}$ range 6.12-4.30.

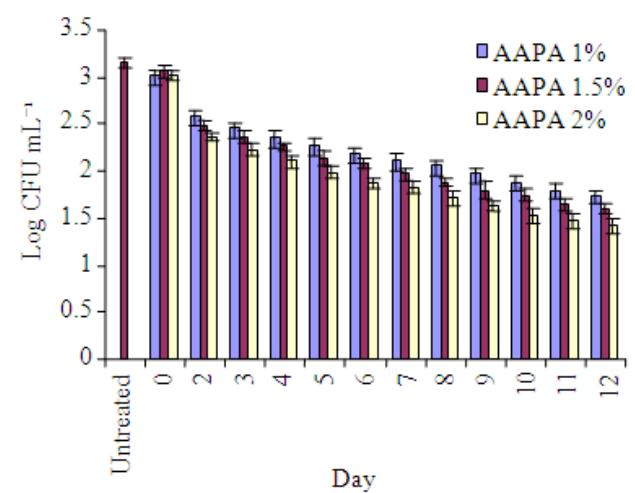

(b)

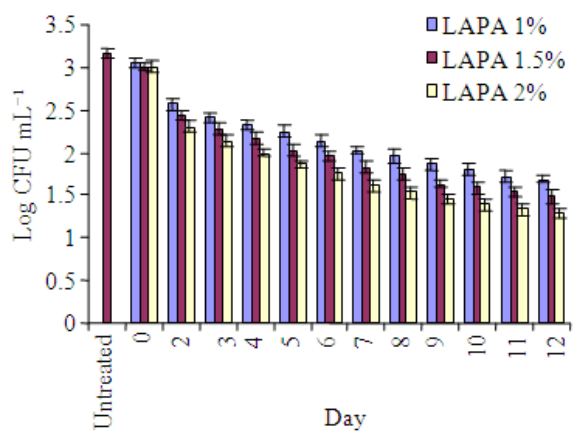

(d)

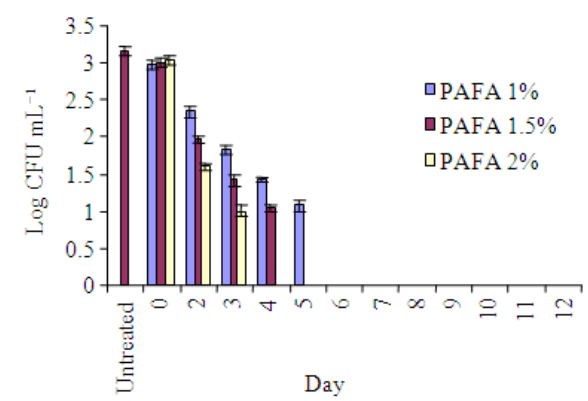

(f)

Fig. 1: Cell number reduction of S. aureus exposed AALA; (a): AAPA; (b): AAFA; (c): LAPA (1-D), LAFA; (e): PAFA; (f): Stored for 12 days. A progressive lowering of E. coli O157:H7 number was detected over time. Dashed line represents the mean untreated 
The mean log reductions of $S$. aureus spray washed with AAFA, LAFA and PAFA at 1, 1.5 and 2\% concentrations were similar, but they could be distinguished by three way interaction analysis (acid $\times$ concentration $\times$ day). Three-way interaction analysis showed that these treatments had different log reductions levels on different days. AAFA at $1,1.5$ and $2 \%$ concentrations on 5 th, 4 th and 3 rd, LAFA at $1 \%$ on 4th, 1.5 and $2 \%$ concentrations on 3 rd, PAFA at $1,1.5$ and $2 \%$ concentrations on 6 th, 5 th and 4 th day of storage respectively. For the treatments which caused $3.16 \log _{10}$ cfu $\mathrm{mL}^{-1}$ reduction of $S$. aureus on 4 th day of storage, differences were found in comparison the level of $\log$ reduction on 3rd day of storage, which were $1.88,1.91$ and $2.16 \log _{10}$ cfu $\mathrm{mL}^{-1}$ reduction for AAFA $1.5 \%$, LAFA $1 \%$ and PAFA $2 \%$ respectively, also the same analysis showed differences of log reductions on 5 th day of storage.

\section{DISCUSSION}

The main goal of this study was to investigate the antibacterial effect of combinations of various organic acids and find a spray wash treatments that decrease the microbial loads of bacteria most efficiently on beef tissue.

The mean $\log$ reductions analysis of bacterial population showed that various organic acids exerted different lethal effects on bacterial population; also, various bacterial species showed different sensitivity to organic acids. Divers factors can be effective on antibacterial activity of organic acids. A study ${ }^{[17]}$ indicated that the degree of bactericidal activity of the different organic acids on the bacterial cell would most probably depend on the presence of the organic compounds, acid concentration, structure of the acid and capacity of a cell to alkalinize the cytoplasm.

Results of various studies showed that the combination of antibacterial agents have stronger antibacterial effect in contrast with each one alone. A study ${ }^{[6]}$ found that the spray wash of contaminated meat with combination of $1.5 \%$ acetic and $1.5 \%$ propionic acids had better lethal effect on $S$. aureus, L. monocytogenes, E. coli and S. typhimurium in contrast with lactic acid $2 \%$. It was indicated that combination of acetic and hydrogen peroxide had greater reduction effect on population of E. coli, Listeria innocua and Salmonella wentworth than each one alone ${ }^{[11]}$. In another research ${ }^{[18]}$, it was found that combination of $2 \%$ lactic acid and $2 \%$ acetic acid reduced population of bacteria on beef more than each one alone.
The $\log$ reductions of bacterial population spray washed with combination of two acids in this study support the findings of previous research. The mean log reductions of $S$. aureus showed that the combination of two organic acids had stronger lethal effect on selected bacteria than each acid individually, which was studied in this laboratory (unpublished data).

Combination of organic acids can cause synergistic antibacterial effect on bacteria. Some researchers explained the mechanism of this synergistic effect is yet unknown ${ }^{[19,17]}$. Some hypotheses can be made for the reason of stronger lethality effect of combination of organic acids in comparison with each one alone. The stronger lethality effect of combination of two organic acids maybe due to the release of more proton ions by acids in aqueous environment when compared with each one alone, or maybe because of increase in the amount of undissociated form of organic acids in the aqueous environment when they are combined together. Another possibility can be hypothesized, when acids are combined together, the resulting suspension possess mixture of different structures of acid molecules. This helps each pair of acids to compensate for the inherent deficit present in the other, thereby augmenting the inoculating power of the combination.

The antibacterial effect of the organic acids was found to be caused mainly by the undissociated form of organic acids ${ }^{[20-22]}$. Two studies ${ }^{[23,24]}$ individually reported that short chain organic acids such as acetic, lactic and citric acids possesses higher bactericidal activity than the non-organic acids such as hydrochloric acid and that bactericidal activity of the organic acids depends mainly on their undissociated form.

Non-dissociated organic acids can passively diffuse through a bacterium's cell wall and once internalized into the neutral $\mathrm{pH}$ of the cell cytoplasm, they dissociate into anions and protons, both of which exert an inhibitory effect on bacteria. Releasing the proton ions cause the internal $\mathrm{pH}$ to decrease, which is incompatible with certain categories of bacteria that do not tolerate an important gradient of transmembranous $\mathrm{pH}^{[21,25-28]}$; also, leading to disruption of proton motive force and inhibiting substrate transport mechanisms ${ }^{[26,28]}$. All these actions of organic acids can negatively affect cell viability.

The reduction rate of $S$. aureus was proportional to the type and the concentration of each treatment. Analysis of variance (ANOVA) for log reduction of $S$. aureus showed that there was a significant difference $(p<0.05)$ between 1, 1.5 and $2 \%$ concentrations of each organic acid. Log reductions analysis showed that the increase in the concentration of organic acids resulted in increasing the antibacterial effect of organic acids. 
Am. J. Infect. Dis., 5 (4): 294-300, 2009

These findings were similar to another study ${ }^{[29]}$ which scrutinized the reduction in the microbial population of E. coli and S. typhimurium exposed to 1, 2 and $3 \%$ concentrations of lactic acid. They found that population reduction of $E$. coli rose by increasing concentration of lactic acid. It was also observed that both 2 and $4 \%$ concentrations of mixture of acetic and lactic acids had inhibitory effect on growth of $E$. coli O157:H7 in ground beef ${ }^{[30]}$. They indicated that $4 \%$ acetic and lactic acids caused stronger reduction effect on population of bacteria ${ }^{[30]}$.

The mean log reductions analysis of $S$. aureus showed that the treatments, which involved formic acid, had stronger reduction effect on the population of studied bacteria. The main reason of the stronger antibacterial effect of these treatments was the existence of formic acid in the mixture. Formic acid is the shortest chain organic acid, which could be beneficial for its diffusion into the cell and cause acidification of the cytoplasm ${ }^{[17,22,31]}$.

There were some differences between antibacterial effect of combinations of acetic and formic, lactic and formic and propionic and formic acids on S. aureus. Two-way interaction (bacteria $\times$ acid) analysis of $\log$ reduction of $S$. aureus treated with combinations of two acids individually showed that there is no significant difference $(p<0.05)$ in the lowering effect of LAFA, AAFA and PAFA treatments. However, they both showed higher $(\mathrm{p}<0.05)$ lowering effect as compared to AAPA, LAPA, AALA treatments.

Analysis of mean log reductions of $S$. aureus population spray washed with all treatments showed that LAFA had the best reduction effect on population of $S$. aureus with more than $3 \log$ reduction in this study. To the best of our knowledge, it was the first time such finding is published in decontaminating meat surface. Interestingly, this treatment showed remarkable antibacterial effect on $S$. aureus inoculated on meat, which is one of the most problematic bacteria in meat industry.

The initial surface $\mathrm{pH}$ of meat, for LAFA treatment showed the lowest $\mathrm{pH}$ value compared with other treatments, so the low $\mathrm{pH}$, which can be because of releasing high number of proton ions in aqueous environment showed the considerable synergistic effect of these two acids on each other which resulted in the strongest lethal effect.

\section{CONCLUSION}

Taken together, the population of $S$. aureus decreased remarkably after spray washing with AALA, AAPA, AAFA, LAPA, LAFA and PAFA treatments.
Among the treatments, these involved formic acid, showed the stronger lethal effect on $S$. aureus than others. LAFA showed the best antibacterial effect on selected bacterium. Collectively, it was concluded that the combination of lactic and formic acids treatment is a feasible and economical method of decontaminating meat.

\section{REFERENCES}

1. Lück and Jager, 1997. Antimicrobial Food Additives: Characteristics, Uses, Effects. SpringerVerlag, Berlin, ISBN: 354061138X, pp: 260.

2. Cherrington, C.A., M. Hinton, G.R. Pearson and I. Chopra, 1991. Short-chain organic acids at $\mathrm{pH}$ 5.0 kill Escherichia coli and Salmonella spp. without causing membrane perturbation. J. Applied Bacteriol., 70: 161-165. PMID: 1902205

3. Smulders, F.J. and G.G. Greer, 1998. Integrating microbial decontamination with organic acid in HACCP programmes from muscle foods: Prospects and controversies. Int. J. Food Microbl., 44: 149-169. PMID: 9851597

4. Kotula, K.L. and R. Thelappurate, 1994. Microbiological and sensory attributes of retail cuts of beef treated with acetic and lactic acid solution. J. Food Protect., 57: 665-670. http://cat.inist.fr/?aModele $=$ afficheN\&cpsidt $=4254$ 470

5. Shrestha, S. and Z. Min, 2004. Effect of lactic acid pretreatment on the quality of fresh pork packed in modified atmosphere. J. Food Eng., 72: 254-260. DOI: 10.1016/j.jfoodeng.2004.12.004

6. Dubal, Z.B., A.M. Paturkar, V.S. Waskar, R.J. Zende and C. Latha et al., 2004. Effect of food grade organic acids on inoculated $S$. aureus, L. monocytogenes, $E$. coli and $S$. typhimurium in sheep/goat meat stored at refrigeration temperature. J. Meat Sci., 66: 817-821. http://cat.inist.fr/?aModele $=$ afficheN\&cpsidt $=1547$ 7292

7. Ransom, J.R., K.E. Belk, J.N. Sofos, J.D. Stopforth, J.A. Scanga and G.C. Smith, 2003. Comparison of intervention technologies for reducing Escherichia coli 0157:H7 on beef cuts and trimmings. Food Protect. Trends, 23: 24-34. http://direct.bl.uk/bld/PlaceOrder.do?UIN=126482 $838 \&$ ETOC $=$ RN\& from $=$ searchengine

8. Castillo, A., L.M. Lucia, D.B. Roberson, T.H. Stevenson, I. Mercado and G.R. Acuff, 2001. Lactic acid sprays reduce bacterial pathogens on cold beef carcass surfaces and in subsequently produced ground beef. J. Food Protect., 64: 58-62. PMID: 11198442 
Am. J. Infect. Dis., 5 (4): 294-300, 2009

9. Jo, S.C., A.R. Rim, H.J. Park, H.G. Yuk and S.C. Lee, 2007. Combined treatment with silver ions and organic acid enhances growth-inhibition of Escherichia coli O157:H7. J. Food Control, 18: 1235-1240.

http://cat.inist.fr/?aModele $=$ afficheN\&cpsidt $=1875$ 0242

10. Beal, J.D., S.J. Niven, A. Campbell and P.H. Brooks, 2004. The effect of copper on the death rate of Salmonella typhimurium DT104:30 in food substrates acidified with organic acids. J. Applied Microbiol., 38: 8-12. PMID: 14687208

11. Bell, K.Y., C.N. Cutter and S.S. Sumner, 1997. Reduction of foodborne micro-organisms on beef carcass tissue using acetic acid, sodium bicarbonate and hydrogen peroxide spray washes. J. Food Microbiol., 14: 439-448.

12. Chowdhury, B.R., S.M. Mukherjee, R. Chakraborty and U.R. Chaudhuri, 2006. Effect of combination pre-treatment on physicochemical, sensory and microbial characteristics of fresh aerobically stored minced goat (Black Bengal) meat organs. Afr. J. Biotechnol., 5: 1274-1283. http://www.academicjournals.org/AJB/PDF/pdf200 6/16Jun/Banani\%20et\%20al.pdf

13. Benson, S.J., 2001. Microbiological Application. A Laboratory Manual in General Microbiology. 8th Edn., The McGraw-Hill Companies, New York, ISBN: 978-0071121699, pp: 652.

14. Dorsa, W.J., 1997. New and established carcass decontamination procedures commonly used in the beef-processing industry. J. Food Protect., 60: 1146-1151.

http://cat.inist.fr/?aModele $=$ afficheN\&cpsidt $=2823672$

15. Samelis J., J.N. Sofos, P.A. Kendall and G.C. Smith, 2005. Survival or growth of Escherichia coli O157:H7 in a model system of fresh meat decontamination runoff waste fluids and its resistance to subsequent lactic acid stress. Applied Environ. Microbiol., 71: 6228-6234.

16. Bjornsdottir, K., F. Breidt and R.F. McFeeters, 2006. Protective effects of organic acids on survival of Escherichia coli O157:H7 in acidic environments. J. Applied Environ. Microbiol., 72: 660-664.

http://www.pubmedcentral.nih.gov/articlerender.fc gi? artid=1352172

17. Chaveerach, P., D.A. Keuzenkamp, H.A.P. Urlings, L.J.A. Lipman and F. van Knapen, 2002. In vitro study on the effect of organic acids on campylobacter Jejuni/coli populations in mixtures of water and feed. Poult. Sci. Assoc., 81: 621-628. http://ps.fass.org/cgi/content/abstract/81/5/621
18. Goddard, B.L., W.B. Mikel, D.E. Conner and W.R. Jones, 1996. Use of organic acids to improve the chemical, physical and microbial attributes of beef strip loins stored at $-1^{\circ} \mathrm{C}$ for 112 days. J. Food Protect., 59: 849-853. http://cat.inist.fr/?aModele $=$ afficheN\&cpsidt=3199 966

19. Malicki, A., W. Zawadzki, S. Bruzewicz, S. Graczyk and A. Czerski, 2004. Effect of formic and propionic acid mixture on Escherichia coli in fish meal stored at $12^{\circ} \mathrm{C}$. Pakistan J. Nutr., 3: 353-356. http://www.pjbs.org/pjnonline/fin236.pdf

20. Dibner, J.J. and P. Buttin, 2002. Use of organic acids as a model to study the impact of gut microflora on nutrition and metabolism. J. Applied Poult. Res., 11: 453-463. http://cat.inist.fr/?aModele $=$ afficheN\&cpsidt=14448724

21. Ricke, S.C., 2003. Perspectives on the use of organic acids and short chain fatty acids as antimicrobials. J. Poult. Sci., 82: 632-639. PMID: 12710485

22. Östling, C.E. and S.E. Lindgren, 1993. Inhibition of enterobacteria and Listeria growth by lactic, acetic and formic acids. J. Applied Bacteriol., 75: $18-24$.

http://cat.inist.fr/?aModele $=$ afficheN\&cpsidt $=3746048$

23. Eklund, T., 1983. The antimicrobial effect of dissociated and undissociated sorbic acid at different pH levels. J. Applied Bacteriol., 54: 383-389. PMID: 6409875

24. Brocklehurst, T.F. and B.M. Lund, 1990. The influence of $\mathrm{pH}$, temperature and organic acids on the initiation of growth of Yersinia enterocolitica. J. Applied Bacteriol., 69: 390-397. PMID: 2246144

25. Jensen B.B., 2001. Possible Ways of Modifying Type and Amount of Products from Microbial Fermentation in the Gut. In: Gut Environment of Pigs, Piva, A., K.E. Bach Knudsen and J.E. Lindberg (Eds.). Nottingham University Press, Nottingham, ISBN: 1-897676-778, pp: 181-200.

26. Smigic, N., A. Rajkovic, D.S. Nielsen,H. Siegumfeldt,M. Uyttendaele, F. Devlieghere. 2009. Intracellular $\mathrm{pH}$ as an indicator of viability and resuscitation of Campylobacter jejuni after decontamination with lactic acid. Int. J. Food Microbiol., 135: 136-143.

27. Young, K.M. and P.M. Foegeding, 1993. Acetic, lactic and citric acids and $\mathrm{pH}$ inhibition of Listeria monocytogenes Scott A and the effect on intracellular pH. J. Applied Bacteriol., 74: 515-520. PMID: 8486558 
28. Russell, J.B., 1991. Resistance of Streptococcus bovis to acetic acid at low $\mathrm{pH}$ : Relationship between intracellular $\mathrm{pH}$ and anion accumulation. Applied Environ. Microbiol., 57: 255-259. http://www.pubmedcentral.nih.gov/articlerender.fc gi? artid $=182694$

29. Anderson, M.E. and R.T. Marshall, 1990. Reducing microbial populations on beef tissues: Concentration and temperature of lactic acid. J. Food Safe., 10: 181-190. http://cat.inist.fr/?aModele $=$ afficheN\&cpsidt $=4367$ 526

30. Conner, D.E., J.S. Kotrola, W.B. Mikel and K.C. Tamblyn, 1997. Effects of acetic-lactic acid treatments applied to beef trim on populations of Escherichia coli $\mathrm{O} 157: \mathrm{H} 7$ and Listeria monocytogenes in ground beef. J. Food Protect., 60: 1560-1563. http://cat.inist.fr/?aModele $=$ afficheN\&cpsidt $=2126$ 734
31. Skrivanova, E., M. Marounek, V. Benda and P. Brezina, 2006. Susceptibility of Escherichia coli, Salmonella sp. and Clostridium perfringens to organic acids and monolaurin. J. Vet. Med., 51: 81-88.

http://www.cazv.cz/attachments/VM_51_81-88.pdf 